\title{
Effectiveness of Group Counseling Using Cognitive and Behavior Therapy Intervention to Reduce Stress among Nurses
}

\author{
Wan Anor Wan Sulaiman ${ }^{1}$, Mohd Dahlan HA Malek ${ }^{1}$, Wan Nor Fatini², Adi Fahrudin ${ }^{3,4, *}$ \\ ${ }^{1}$ Faculty of Psychology and Education, University Malaysia Sabah, Malaysia \\ ${ }^{2}$ Universiti Tun Abdul Razak (UNITAR), Malaysia \\ ${ }^{3}$ Faculty of Social and Political Science, University of Muhammadiyah Jakarta, Indonesia \\ ${ }^{4}$ Social Work Program, Faculty of Psychology and Education, University Malaysia Sabah, Malaysia
}

Copyright $\subseteq 2017$ by authors, all rights reserved. Authors agree that this article remains permanently open access under the terms of the Creative Commons Attribution License 4.0 International License

\begin{abstract}
This study was conducted as to explore the effectiveness of the treatment modules in group counselling between the Cognitive Therapy Group Counselling and Behavior Therapy Group Counselling in reducing stress level among nurses in Women and Children Hospital in Kota Kinabalu. There are two objectives that guided this mixed methods study. Firstly, this study was to test the effectiveness of the Cognitive Therapy Group Counselling (CTGC) by looking at the different between pre-test and post-test results on the level of stress among nurses who have followed the CTGC with nurses who did not follow the CTGC (control group). Secondly, this study was to test the effectiveness of the Behavior Therapy Group Counselling (BTGC) by looking at the different between pre-test and post-test results on the level of stress among nurses who have followed the BTGC with nurses who did not follow the BTGC (control group). The results showed that there was a significance difference on the level of stress between nurses who joined either GCCT and GCBT with those nurses who did not join the treatment (Control group). In fact, nurses who have joined either treatment have shown some decrease in their stress level. However, when comparing between the two (CTGC and BTGC), BTGC showed better results in reducing stress level among nurses in the hospital. Therefore, both CTGC and BTGC are suitable to reduce stress among nurses in the hospital.
\end{abstract}

Keyword Stress, Nurse, Group Counselling, Cognitive and Behaviour Therapy

\section{Introduction}

Stress at work is not something new in all working places. There are numerous studies have been conducted on the effects of stress at work and organizations. Stress could cause negative effects on mental illness among the workers (Ursin \& Eriksen, 2004). A national level studies by American Psychological Association (APA) in 2007, have found that stress could contribute health problems, ruin relationships, and work productivity. They also found that, stress is one of leading problem towards health issues which one third of the Americans are suffering from (APA, 2007). Malaysia is in need of highly competitive, efficient, and active workers to be a developed country as manifested in Vision 2020. Therefore, stress among the workers is an obstacle to good work productivity. Cooper and Marshall (1976) suggested that, pressure among workers will effect on their physical and psychological. Work pressure is also seen as a major contributor to truancy, low moral value, high accidence, and most of all reduction in productivity.

Nurses are directly in contact with chronic diseases and death. This profession is truly a challenging job compare to other jobs (Shen et. al., 2005; Sveinsdottir et. al., 2006). Previous research findings have proven that, pressure among the nurses is the results from exposure to multiple factors related to working environment and personal factors (Kawano, 2008) in Wu et. al. (2010). Since the previous studies have proven that the pressure among the nurses is really serious and requires variety of strategies to overcome this problem from over escalating. A study done by Hui Wu et. al. (2009) has shown that nursing is a highly demanding job and affected their physical and mental health. Besides that, the pressure is believed to derive from the combination of working environment and personal problems.

Statement of problems in this study is concerning the pressure facing by the nurses. This pressure has becoming a threat in providing services to all patients at the hospital. It has been proven by many studies in the previous that, this profession has potential in contributing stress at work.

Stress among the nurses has been studied excessively 
since the last decade and is an international phenomenon (Chang et. al., 2005). Nurses are a group of workers who are known for their working pressure, a study conducted by Chang et. al. (2005) has proven that. Factors that are related to pressure at working place are; poverty, dramatic changes in working environment, inadequate resources and staffs, and managing death. Sharifah Zainiyah, Afiq Im, Chow Cy \& Siti Dara (2011), have conducted a study on 110 nurses in Kuala Lumpur Hospital and have found that $75.4 \%$ of them were having normal stress while $24.6 \%$ are having stress in their work.

The group counselling role in reducing work pressure has been given priority in this study. The main factor that contributes to this study is the effectiveness of group counselling in reducing stress at work based on the result of previous studies. The advantages of group counselling is not just able to be used to reduce stress level but also have been used by local researchers in treating other problems such as social anxiety (Wan Abdul Kadi, 1994).

It is important when applying a group counselling to base on theories in order to ensure the effectiveness in reducing stress. Two different approaches of group counselling were used as intervention to treat stress in this study. The first group counselling was based on cognitive approach while the second group counselling was using behavioural approach. The objective of using cognitive approach is to teach the individual to identify, evaluate, and to change the dysfunctional thoughts and their own believes (Seligman, et. al, 2010). While the behavioural approach objective is to resolve the problem based on its characteristics and history, exploring the context of undesirable behaviours, increasing the basic strength of behaviours, monitoring the frequency of certain behaviours within a time frame, and targeted behaviour. The determine objective must be realistic, clear, specific and can be assessed. Besides that, it also should be meaningful and positive to clients (Seligman, 2010).

Consequently, the statement of problem in this study is related to the implication of intervention to reduce stress level by using a strong theoretical foundation. He intended interventions to be used is group counselling with cognitive, and behavioural approaches. Whatsoever, a question has raised, does group counselling with a certain approach could successfully reduce the stress among nurses? This is due to the notion that, stress among the nurses ought to be treated in order to ensure a good and quality services offered. Roup counselling must be conducted by scientific approach with empirical characteristics. Hence, all these three research problems will be answered through interventions and treatments in group counselling by two different types of approaches. Namely, cognitive orientated and behavioural oriented approaches. All changes emerge from these method of treatments will be measured by the nurses' level of stress displayed.

\section{Aims of the Study}

This study is aimed to examine the effect of Cognitive Therapy Group Counselling (CTGCC) and Behavioural Therapy Group Counselling (BTGC) on stress among the nurses. The aims of the study are as follows:

a To measure the effect of Cognitive Therapy Group Counselling (CTGCC) intervention on dependant variable's stress level among the nurses.

b To measure the effect of Behavioural Therapy Group Counselling (BTGCC) intervention on dependent variable's stress level among the nurses.

c To measure the effect of Cognitive Therapy Group Counselling (CTGCC) intervention on stress between the experiment group and control group.

d To measure the effect of Behavioural Therapy Group Counselling (BTGCC) intervention on stress between the experiment group and control group.

\section{Significance of the Study}

This study is hoped to prove the effectiveness of group counselling as a way to handle and manage stress among the workers. It provides a clear scheme of using group counselling effectively in helping nurses to who are suffering from of stress and also providing guidelines to help nurses who are having unsolved state of stress. It is hoped that the managing department could apply this treatment which has been tested for its reliability in the effort to reduce stress and to increase productivity, work satisfaction, and life quality among the hospital workers.

It is also hoped that the results of this study could somewhat produce some workers who are capable to manage their stress well. The treatment given is hoped to be able to reduce the stress at hand which has become a major obstacle in good productivity. The treatment given to those workers who were having high level of stress was meant to reduce truancy, psychological problems and at the same to increase their productivity.

Data on stress facing by nurses collected in this study is hoped to be used in suitable and relevant national programs, rules and regulations in preparing the best services by nurses in especially in government hospitals. This effort is meant to build a good working relationship between employers and employees which could somehow increase the productivity and at the same time the nation as well. Other than that, this experimental study which was based its orientation on specific theoretical aspects and application models is hoped to strengthen the role of theoretical and the used of Group Counselling Model in counselling processes. 


\section{Methodology}

\section{Research Design}

This study is using quasi experimental research design to examine the stress level different among the nurses who were grouped under two treatment groups and one control group. The two experimental groups will undergo six group counselling sessions for six weeks. Each session is scheduled for not more than two hours. Whereby, the control group will not have to undergo any treatment sessions until this study has completed.

\section{Samples}

Respondents of this study consist of 170 nurses from Women and Children Hospital in Likas, Kota Kinabalu. 36 nurses who were identified as having higher level of stress were then divided into two different groups ( $n 12$ in each group) who will undergo Cognitive Therapy counselling group and Behavioural Therapy counselling group respectively, while the other 12 respondents are in the control group.

Table 1. Respondents according to gender, age, and race

\begin{tabular}{|c|c|c|c|}
\hline \multicolumn{2}{|c|}{ Demographic } & Frequency & $\begin{array}{c}\text { Percentage } \\
(\mathbf{1 0 0} \%)\end{array}$ \\
\hline \multicolumn{2}{|c|}{ Respondents $(\boldsymbol{n})$} & $\mathbf{1 7 0}$ & \\
\hline \multirow{3}{*}{ Gender } & Male & 1 & 0.6 \\
\cline { 2 - 4 } & Female & 169 & 99.4 \\
\hline \multirow{4}{*}{ Race } & Malay & 30 & 17.6 \\
\cline { 2 - 4 } & Chinese & 2 & 1.2 \\
\cline { 2 - 4 } & Indian & 9 & 5.3 \\
\cline { 2 - 4 } & Others & 129 & 75.9 \\
\hline \multirow{4}{*}{ Age } & 20 to 30 & 96 & 56.6 \\
\cline { 2 - 4 } & 31 to 40 & 47 & 27.6 \\
\cline { 2 - 4 } & 41 to 50 & 22 & 12.9 \\
\cline { 2 - 4 } & 51 to 60 & 5 & 2.9 \\
\hline
\end{tabular}

Table 2. Stress level among nurses (n 170)

\begin{tabular}{|c|c|c|c|}
\hline $\begin{array}{c}\text { Dependent } \\
\text { Variables }\end{array}$ & Frequency & Percentage (\%) & Tahap \\
\hline \multirow{4}{*}{ Stress Level } & Mild & 10 & 5.9 \\
\cline { 2 - 4 } & Moderate & 79 & 46.4 \\
\cline { 2 - 4 } & Severe & 77 & 45.3 \\
\cline { 2 - 4 } & $\begin{array}{c}\text { Extremely } \\
\text { Severe }\end{array}$ & 4 & 2.4 \\
\hline
\end{tabular}

\section{Location}

This study was conducted at Women and Children Hospital, in Likas, Kota Kinabalu Sabah. This hospital was chosen based on its high density of nurses which exceeding 1100 persons compared to any other hospitals in the state of
Sabah. Besides it is locate in the state capital of Sabah.

\section{Measurement Tool}

Depression Anxiety Stress Scales (DASS) by Lovibond and Lovibond (1996) was used as the measurement tool in this study. This survey consists of two sections, namely section A and section B. Reliability of DASS was measured by using alpha Cronbach which carries a value of 0.909 .

\section{Data Analysis}

Researchers have using non parametric data analysis in analysing the data gathered. This was due to the characteristics of the data which was not normal and the sample size was below 30. Pre-test and post-test data were conducted to examine the effects different before and after the treatments on the stress level of the dependent variables between treatment groups of CTGCC and BTGC and CG. Few types of analysis techniques were used to analyse the pre-test and post-test, as follows:

a Wilcoxon Signed Rank Test analysis was used to compare between a value of a single group to a pair of similar groups.

b Mann-Whitney Test analysis was used to compare between two different groups in measuring the main variables which were between CTGCC and BTGCC, CTGCC and CG and BTGCC and CG at post-test level.

c Kruskal-Walis analysis was used to compare between three or more different groups.

\section{Results}

This study was conducted to examine the effectiveness of Cognitive Therapy Group Counselling (CTGC) and Behavioural Therapy Group Counselling (BTGC) modules on stress dependent variables. The discussion part of this study will focus on the results derived from the measurement of studied variables which are independent variables (treatment groups) and dependent variable (stress).

Table 3. Behavioral Therapy Group Counselling (BTGC)

\begin{tabular}{|c|c|c|c|}
\hline \multicolumn{2}{|c|}{ Demographic } & Frequency & Percentage (\%) \\
\hline Gender & (Female) & 12 & 100 \\
\hline \multirow{3}{*}{ Age } & 20 to 30 & 4 & 33.3 \\
\cline { 2 - 4 } & 31 to 40 & 2 & 16.6 \\
\cline { 2 - 4 } & 41 to 50 & 6 & 50.1 \\
\hline \multirow{3}{*}{ Education Level } & Diploma/STPM & 7 & 58.3 \\
\cline { 2 - 4 } & SPM & 5 & 41.7 \\
\hline \multirow{3}{*}{ Marital Status } & Single & 5 & 41.6 \\
\cline { 2 - 4 } & Married & 6 & 50.0 \\
\cline { 2 - 4 } & Devoiced & 1 & 8.3 \\
\hline
\end{tabular}


Table 4. Cognitive Therapy Group Counselling Cluster (CTGCC)

\begin{tabular}{|c|c|c|c|}
\hline \multicolumn{2}{|c|}{ Demographic } & Frequency & $\begin{array}{c}\text { Percentage } \\
(\%)\end{array}$ \\
\hline Gender & (Female) & 12 & 100 \\
\hline \multirow{4}{*}{ Age } & 20 to 30 & 4 & 33.3 \\
\cline { 2 - 4 } & 31 to 40 & 2 & 16.6 \\
\cline { 2 - 4 } & 41 to 50 & 5 & 41.6 \\
\cline { 2 - 4 } & 51 to 60 & 1 & 8.3 \\
\hline \multirow{4}{*}{$\begin{array}{c}\text { Education } \\
\text { Level }\end{array}$} & Diploma/STPM & 6 & 50.0 \\
\cline { 2 - 4 } & SPM & 4 & 33.3 \\
\cline { 2 - 4 } & Bachelor Degree & 1 & 8.3 \\
\cline { 2 - 4 } & Post Graduate & 1 & 8.3 \\
\hline \multirow{3}{*}{\begin{tabular}{c} 
Marital Status \\
\cline { 2 - 4 }
\end{tabular}} & Single & 2 & 16.6 \\
\cline { 2 - 4 } & Married & 10 & 83.3 \\
\hline
\end{tabular}

Table 5. Control Group Cluster (CFC)

\begin{tabular}{|c|c|c|c|}
\hline \multicolumn{2}{|c|}{ Demographic } & Frequency & $\begin{array}{c}\text { Percentage } \\
\text { (\%) }\end{array}$ \\
\hline Gender & (Female) & 12 & 100 \\
\hline \multirow{4}{*}{ Age } & 20 to 30 & 4 & 33.3 \\
\cline { 2 - 4 } & 31 to 40 & 2 & 16.6 \\
\cline { 2 - 4 } & 51 to 60 & 1 & 8.3 \\
\hline \multirow{4}{*}{$\begin{array}{c}\text { Education } \\
\text { Level }\end{array}$} & Diploma/STPM & 6 & 50.0 \\
\cline { 2 - 4 } & SPM & 3 & 25 \\
\cline { 2 - 4 } & Bachelor Degree & 1 & 8.3 \\
\cline { 2 - 4 } & Post Graduate & 2 & 16.6 \\
\hline \multirow{3}{*}{ Marital Status } & Single & 5 & 41.6 \\
\cline { 2 - 4 } & Married & 7 & 58.3 \\
\hline
\end{tabular}

Table 6. Pre-Test and Post-Test effects on nurses in the Cognitive Therapy Group Counselling Cluster (CTGCC)

\begin{tabular}{|c|c|c|c|c|c|}
\hline Variables & $\boldsymbol{n = 1 2}$ & & Stress & & \\
\hline & & Mean & $\begin{array}{c}\text { Standard } \\
\text { Deviation }\end{array}$ & $\boldsymbol{Z}$ & $\boldsymbol{P}$ Value \\
\hline & 12 & 32.25 & 2.22 & & \\
\hline POST & 12 & 2.75 & 4.41 & & \\
\hline$(\mathrm{r}=-0.89)$. & & & & & \\
\hline
\end{tabular}

*significance level: $\mathrm{p}<0.05$

Wilcoxon Signed Rank Test showed that there has been reduction in stress level among the nurses after went through Cognitive Therapy Group Counselling (CTGCC), $z=-3.06$, $p<.0002$, with a huge size of effect $(r=-0.89)$. Mean score for stress among nurses shown reduction from pre-test programme (mean=32.25) to post-test programme $($ mean $=2.75)$. It shown that there is a significance difference between the effect of treatments after the pre-test and post-teston stress among those nurses who have taken part in the Cognitive Therapy Group Counselling (CTGC)
Table 7. Pre-test and Post-Test Different among Nurses in the Behavioural Therapy Group Counselling (BTGC)

\begin{tabular}{|c|c|c|c|c|c|}
\hline Variables & $\boldsymbol{n}=\mathbf{1 2}$ & & Stress & & \\
\hline & & Mean & $\begin{array}{c}\text { Standard } \\
\text { Deviation }\end{array}$ & $\boldsymbol{z}$ & $\boldsymbol{P}$ Value \\
\hline PRE & 12 & 38.08 & 1.88 & & \\
\hline & & & & -3.07 & $0.002 *$ \\
\hline POST & 12 & 4.41 & 4.01 & & \\
\hline $\mathrm{r}=-0.89$ & & & & & \\
\hline
\end{tabular}

*significance level: $\mathrm{p}<0.05$

Wilcoxon Signed Rank Test analysis has shown that there was a reduction in stress level among the nurses after they have followed Behavioral Therapy Group Counselling (BTGCC), $\mathrm{z}=-3.07, \mathrm{p}<.0002$, with huge effect $(\mathrm{r}=-0.89)$. The mean score on stress among those nurses decreased from re-test program $($ mean $=38.08)$ to post-test program $($ mean $=$ 4.41). It shows that, there is different on stress level in post-test between those nurses who have followed Cognitive Therapy Group Counselling (CTGCC) and Behavioural Therapy Group Counselling (BTGC).

Table 8. Mean Score Different in pre-test and post-test on Control Group (CG)

\begin{tabular}{|c|c|c|c|c|c|}
\hline Variables & $\boldsymbol{n = 1 2}$ & & Stress & & \\
\hline & Mean & $\begin{array}{c}\text { Standard } \\
\text { Deviation }\end{array}$ & $\boldsymbol{Z}$ & $\begin{array}{c}\boldsymbol{P} \\
\text { value }\end{array}$ \\
\hline PRE & 12 & 31.08 & 1.50 & & \\
\hline & & & & -1.00 & 0.317 \\
\hline POST & 12 & 30.91 & 1.62 & & \\
\hline
\end{tabular}

*significance level $\mathrm{p}<0.05$

Wilcoxon Signed Rank Test analysis did not show much reduction in stress level among the nurses before and after they have put into the Control Group (CG) $\mathrm{z}=-1.00, \mathrm{p}>.317$, with huge effect size $(r=-0.29)$. The mean score on stress level among the nurses declined from pre-test $($ mean $=31.08)$ to post-test (mean $=30.91$ ). It shows that, there is different between pre-test and post-test results in the nurses' stress level who were in the control group (CG). It shows that, there is different between pre-test and post-test results in the nurses' stress level who were in the control group (CG).

Table 9. Post-test Different for Nurses in the Cognitive Therapy Group Counselling Cluster (CTGCC) and Behavioural Therapy Group Counselling (BTGC).

\begin{tabular}{|c|c|c|c|c|c|}
\hline Variables & $\boldsymbol{n}=\mathbf{2 4}$ & & Stress & & \\
\hline & & $\begin{array}{c}\text { Mean } \\
\text { rank }\end{array}$ & $\begin{array}{c}\text { Sum } \\
\text { rank }\end{array}$ & $\boldsymbol{z}$ & $\boldsymbol{P}$ Value \\
\hline BTGC & 12 & 15.46 & 1.88 & & \\
\hline & & & & -3.07 & $0.037^{*}$ \\
\hline & & & & & \\
\hline CTGCC & 12 & 9.54 & 4.01 & & \\
\hline
\end{tabular}

*significance level $p<0.05$ 
Mann-Whitney Test analysis shows that there is different in stress level reduction among the nurses after took part in the Cognitive Therapy Group Counselling (CTGCC) and Behavioural Therapy Group Counselling. (BTGC), $z=-1.00$, $p<0.037$, with big effect size $(r=-0.34)$. The stress level mean score for nurses in the Behavioural Therapy Group Counselling $(\mathrm{BTGC})$ is higher (mean $=15.46)$ in comparison to the mean score found among the nurses from Cognitive Therapy Group Counselling (CTGCC) which is (mean = 9.54). It shows that, Cognitive Therapy Group Counselling (CTGCC) is more effective compared to Behavioural Therapy Group Counselling (BTGC). It also means that, there is different in stress level reduction between those nurses who have followed Cognitive Therapy Group Counselling and Behavioural Therapy Group Counselling with the Control Group.

Table 10. Different in Post-Test Results between Nurses in the Cognitive Therapy Group Counselling (CTGCC) and Control Group (CG).

\begin{tabular}{|c|c|c|c|c|c|}
\hline Variables & $\boldsymbol{n}=\mathbf{2 4}$ & & Stress & & \\
\hline & & $\begin{array}{c}\text { Mean } \\
\text { rank }\end{array}$ & $\begin{array}{c}\text { Sum } \\
\text { rank }\end{array}$ & $\boldsymbol{z}$ & $\boldsymbol{P}$ Value \\
\hline CTGCC & 12 & 6.50 & 6.50 & & \\
\hline & & & & -4.194 & $0.000^{*}$ \\
\hline CG & 12 & 18.50 & 18.50 & & \\
\hline
\end{tabular}

*significance level $\mathrm{p}<0.001$

Mann- Whitney Test analysis shows that there is a difference in stress level reduction among the nurses in the Cognitive Therapy Group Counselling (CTGCC), $\mathrm{z}=$ $-4.994,>0.000$, with big effect size $(r=-0.86)$. Mean score for stress among the nurses in Control Group (CG) is much higher $($ mean $=18.50)$ comparing to the median score on stress level among the nurses in Cognitive Therapy Group Counselling $(\mathrm{CTGCC})$ which is (mean $=6.50)$. It shows that Cognitive Therapy Group Counselling is more effective in comparison to the Control Group. Therefore the hypothesis is rejected.

Table 11. Differences on nurses' stress level Post-Test in the Behavioural Therapy Group Counselling (BTGC) and Control group (CG).

\begin{tabular}{|c|c|c|c|c|c|}
\hline Variables & $\boldsymbol{n}=\mathbf{2 4}$ & & Stress & & \\
\hline & & $\begin{array}{c}\text { Mean } \\
\text { rank }\end{array}$ & $\begin{array}{c}\text { Sum } \\
\text { rank }\end{array}$ & $\boldsymbol{z}$ & P Value \\
\hline BTGC & 12 & 6.50 & 6.50 & & \\
\hline & & & & -4.194 & $0.000^{*}$ \\
\hline & & & & & \\
\hline CG & 12 & 18.50 & 18.50 & & \\
\hline
\end{tabular}

*significance level $\mathrm{p}<0.001$

Mann-Whitney Test analysis shows that, there is a different in stress reduction between the nurses who took part in the Cognitive Therapy Group Counselling (CTGCC) and the Control Group (CG), $\mathrm{z}=-4.194, \mathrm{p}>0.000$, with big size effect $(r=-86)$. The mean score for nurses in the Control Group $(C G)$ is much higher (mean $=18.50)$ compared to the median score or the nurses in the Cognitive Therapy Group
Counselling $($ mean $=6.50)$. It shows that Cognitive Therapy Group Counselling is more effective compared to the Control Group.

\section{Discussion and Conclusions}

\section{The Effect of Cognitive Therapy Group Counselling on Stressed Nurses (Treatment)}

Findings from this study revealed that, there are significant differences from the treatments between pre-test and post-test on those nurses who were in the Cognitive Therapy Group Counselling. It was found that, their stress level has deceased after completed the sessions. The same findings were also found by Her Kim and friends (2013) in their study on stress among the nurses by using Cognitive Therapy in awareness program activities (b-MBCT) with a marginal mean of 3.14; $\mathrm{p}=.002$ upon the completion of b-MBCT. The results of the current study are also similar to the findings from Pipe et. al. (2009) and Mackenzie's (2006), who studied on the stress reduction in nurses, and also Phang et. al., (2013) who have studied on medical students. MBCT Intervention is also effective in reducing stress and at the same time promoting wellness, either in clinical or non-clinical fields (Gold, et. al., 2010).

Besides that, the findings of this study also show that are significance differences between on the effects of treatments or post-test on Cognitive Therapy Group Counselling (CTGCC) and Behavioural Therapy Group Counselling (BTGC).

This study has been using two different types of module in reducing stress level among the nurses. Although both modules have shown positive reduction in stress level among the nurses, nevertheless, it was found that Cognitive Therapy Group Counselling is more effective in comparison to Behavioural Therapy Group Therapy. It proves that, Cognitive Therapy Group Counselling is more suitable in reducing stress level among nurses compared to Behavioural Therapy Group Counselling, this is due to the stress nature which involving one's way of thinking. Everyone has their own way of thinking since it involves one's intellectuality. If stress was viewed in a positive perspective, the outcomes would be in positive as well and likewise.

Cognitive Therapy is a type of therapy which is using a active, collaborative, problem orientate, and relative approaches in providing treatment for a short time frame. He most prominent view regarding this therapy is that, it is assumed that this therapy could provide effect as moderator to cognitive changes which involving way of thinking, believe and scheme, and emphasises on cognitive changes. What so ever, Cognitive Therapy uses direct strategy with other few behavioural modifications approaches in order to change one's way of thinking (for example, situations to create panic stimuli, scheduled activities, and social skills exercises). Thus, the basis of this strategy is to create changes in the dysfunctional cognitive structure of the client 
(Beck, et. al., 2013).

Beck and colleagues have used cognitive therapy as a major model apart from CBT approach (Beck, 2005). This model emphasises on changes caused by the undesirable stress. Cognitive Therapy is also a study on the basis of epistemology. According to Beck (1997), a systematic view on Cognitive Therapy has concluded that, this therapy is very effective to treat variety of mental illness and problems (for examples; depression, anxiety symptom, eating disorders, and sexual dysfunctional). As another examples, Robinson, Berman, and Neimeyer (1990), have conducted a meta-analysis study to examine the effectiveness of Cognitive Therapy on depression, have found that this therapy could control the situation in a much early stage compared to other therapies.

There are 16 studies on meta-analysis have been made to support the effectiveness of Cognitive Therapy n multiple psychological conditions these include, depression, unipolar and bipolar anxiety, panic disorders, obsessive-compulsive disorder, social anxiety disorders, psychotic related schizophrenia, and bulimia nervosa (Butler, Chapman, Forman, \& Beck, 2006). On the other hand, there are also other approaches which have similar characteristics with Cognitive therapy, this is including the basis of observations which emphasis on collaborative, and an active therapeutic relation. It also provides the importance of certain process which is not conducted in general as a bench mark in this therapy, for instance experience acceptance, observations, and value descriptions (Forman \& Herbert, 2007; Hayes, Follette, \& Linehan, 2004).

\section{The Effect of Behavioural Therapy Group Counselling on Stressed Nurses (Treatment)}

Findings from this study revealed that, there is significant differences from the treatments between pre-test and post-test on those nurses who were in the Behavioural Therapy Group Counselling. It was found that, their stress level has deceased after completed the sessions. The same findings were found and related to the study on the effectiveness of using Behavioural Therapy in treating stress for temporomandibular joint pain síndrome patients. Alden and Lundgren (2004), have conducted a study using Behavioural Therapy on clients who wanted to reduce their weight. Other studies using the same Behavioural Therapy is Buch (1995) on parents with autism children; Steele (1989) also has used the same therapy on clients with obsessive compulsives.

\section{Conclusions}

The current study has proven that the used of Cognitive Therapy Group Counselling and Behavioural Therapy Group Counselling have reduced stress suffered by hospital nurses. Both approaches have been applied in experimental method for the duration of six weeks and cognitive and behavioural counselling techniques have been used in the treatment process. As a comparison on its effectiveness, both approaches were also later used on the Control Group. The findings of this study have shown that Cognitive Therapy Group Counselling is more effective in reducing stress among the nurses. Therefore, it is hoped that these findings could be used and applied on all the nurses who are suffering from high level of stress so that it would help them to live their life better, achieving work satisfaction, and able to increase the organisation productivity.

\section{REFERENCES}

[1] Beck, G, Castonguay, L, Chronis-Tuscano, Klonksy, D., McGinn, L..K, \& Youngstrom, E. (2012). Giving Students a Fish Versus Teaching Students to Fish: Evidence-Based Training Principles and Practical Guidelines. Panel Discussion at the annual convention of the Association for Behavioral and Cognitive Therapies, Baltimore, MD

[2] Beck, A. T. (1997). The past and future of cognitive therapy. Journal of Psychotherapy Practice and Research, 6, 276-284

[3] Butler A, Jason E. Chapman b, Evan M. Forman c, Aaron T. Beck a (2006). The empirical status of cognitive-behavioral therapy: A review of meta-analyses. Clinical Psychology Review 26 (2006) $17-31$

[4] Chang, John W. Bidewell ${ }^{\mathrm{a}}$, John Daly ${ }^{\mathrm{a}}$, International Journal of Nursing Studies Volume 44, Issue 8, November 2007, Pages 1354-1362

[5] Cooper, C.L., \& Marshall, J. (1976). Occupational Source of Stress. A Review of the Literature Relating to Coronary Heart Disease and Mental Ill-Health. Journal of Occupational Psychology, 49: 11-28.

[6] Forman, E., \& Herbert, J. D. (2007). Comparing and contrasting cognitive behavior therapyand acceptance and commitment therapy: Theory, technology, effectiveness, and mechanisms. Manuscript submitted for publication

[7] Gold, E., Smith, A., Hopper, I., Herne, D., Tansey, G. and Hulland, C. (2010). Mindfulness-based stress reduction (MBSR) for primary school teachers. Journal of Child and Family Studies, 19(2):184-189.

[8] Hayes, S. C., Follette, V. M., \& Linehan, M. M. (Eds.). (2004). Mindfulness and acceptance: Expanding the cognitive-behavioral tradition. New York: Guilford Press

[9] Kawano Y (2008). Association of job-related stress factors with psychological and somatic symptoms among Japanese hospital nurses: effect of departmental environment in acute care hospitals; J Occup Health.; 50 (1): 79-85.

[10] Linda Selegman, Lourie W, Reichenberg (2010) Theories of counselling and psychotherapy systems, strategies and skill. Third edition. Pearson New York.

[11] Lovibond dan Lovibond (1996)Manual for the depression anxiety stress scales / S.H. Sydney, N.S.W. : Psychology Foundation of Australia, - Psychology Foundation 
[12] Mackenzie, C.S., Poulin, P.A. and Seidman-Carlson, R. (2006). A brief mindfulness-based stress reduction intervention for nurses and nurse aides. [Randomized Controlled Trial]. Applied nursing research: ANR, 19(2):105-109.

[13] Phang, C.K. and Oei, T.P.S. (2012). "From Mindfulness to Meta-mindfulness: Further Integration of Meta-mindfulness Concept and Strategies into Cognitive-Behavioral Therapy." Mindfulness: 1-13.

[14] Pipe, T., Bortz, J., Dueck, A., Pendergast, D., Buchda, V., \& Summers J. (2009). Nurse leader mindfulness meditation program for stress management: A randomized controlled trial. Journal of Nursing Administration, 39(3), 130-137.

[15] Robinson, L. A., Berman, J. S., \& Neimeyer, R. A. (1990). Psychotherapy for the treatment of depression: A comprehensive review of controlled outcome research. Psychological Bulletin, 108, 30-49.
[16] Sharifah Zainiyah and I. M., Afiq and Chow, C. Y. and D., Siti Sara (2011) Stress and its associated factors amongst ward nurses in a public hospital Kuala Lumpur. Malaysian Journal of Public Health Medicine, 11 (1). pp. 78-85. ISSN $1675-0306$

[17] Shen, H.-C., Cheng, Y., Tsai, P.-J., Lee, S.S., Guo, Y.L., 2005. Occupational stress in nurses in psychiatric institutions in Taiwan. J. Occup. Health 47, 218-225.

[18] Sveinsdottir, H., Biering, P., Ramel, A., 2006. Occupational stress, job satisfaction, and working environment among Icelandic nurses. Int. J. Nurs. Stud. 43, 875-889

[19] Ursin H, Eriksen HR. The cognitive activation theory of stress. Psychoneuroendocrinology. 2004; 29(5):567-92

[20] Wan Abdul Kader Wan Ahmad. (1994). Kaunseling Kelompok. Pengurangan kebimbangan Sosial. Kuala Lumpur. Dewan Bahasa dan Pustaka. 